\title{
Too Sweet/Too Fatty Food Consumption: Determinants among Secondary School Pupils in the City of Bobo-Dioulasso (Burkina Faso)
}

\author{
Téné Marceline Yaméogo ${ }^{1,2^{*}}$, Mireille Marie Déborah Tapsoba1, Aimée Senkaye-Lagom Kissou1,2, \\ Bazoumana Coulibali'1, Issiaka Sombié1, Carole Gilberte Kyelem ${ }^{1,2}$, Alassane Ilboudo², \\ Omar Guira3 ${ }^{3}$, Djingri Lankoandé2, Abraham Bagbila², Marina Birba², \\ Macaire Sampawindé Ouédraogo ${ }^{1,2}$, Youssouf Joseph Drabo ${ }^{3}$
}

${ }^{1}$ INSSA, University Nazi Boni, Bobo-Dioulasso, Burkina Faso

${ }^{2} \mathrm{CHU}$ SouroSanon, Bobo-Dioulasso, Burkina Faso

${ }^{3}$ UFR-SDS, University Joseph Ki Zerbo, Ouagadougou, Burkina Faso

Email: *teneline@gmail.com

How to cite this paper: Yaméogo, T.M., Tapsoba, M.M.D., Kissou, A.S.-L., Coulibali, B., Sombié, I., Kyelem, C.G., Ilboudo, A., Guira, O., Lankoandé, D., Bagbila, A., Birba, M., Ouédraogo, M.S. and Drabo, Y.J. (2018) Too Sweet/Too Fatty Food Consumption: Determinants among Secondary School Pupils in the City of Bobo-Dioulasso (Burkina Faso). Open Journal of Pediatrics, 8, 126-133.

https://doi.org/10.4236/ojped.2018.82015

Received: April 15, 2018

Accepted: May 11, 2018

Published: May 14, 2018

Copyright (c) 2018 by authors and Scientific Research Publishing Inc. This work is licensed under the Creative Commons Attribution International License (CC BY 4.0).

http://creativecommons.org/licenses/by/4.0/

\begin{abstract}
Introduction: Nutrition, particularly when too sweet or too fatty, is a major determinant of chronic diseases. This study aims to determine the frequency and associate factors of the excessive consumption of sweet drinks and fried food among secondary school pupils. Methods: It is cross-sectional study which was conducted from March to April 2016 among 1st, 4th and 7th form pupils of public and private schools in the city of Bobo-Dioulasso. Nutritional investigation methods consisted in a reminder of the last 24 hours associated with a questionnaire on food consumption frequency. Excessive consumption of sweet drinks was defined as a consumption of more than 3 sweet drinks (soda) or sugary juice per day $(\sim 33 \mathrm{cl} \times 3)$; and excessive consumption of fried food as a consumption of more than 1 intake of fried food per day. Results: In total, 1993 pupils were interviewed. The mean age was $17.5 \pm 3.6$ years and sex-ratio 0.7. Excessive consumption of sweet drinks and fried food was recorded in $12.7 \%(\mathrm{n}=253)$ and $28.2 \%(\mathrm{n}=561)$ of pupils, respectively. The factors associated with excessive consumption of sweet drinks were: sex/female, sedentarily, desire to gain weight, lean or normal corpulence of the mother and breakfast intake; those associated with excessive consumption of fried food were: sex/female, being in 1st or 4th form, physical exercise practice and breakfast intake. But the fact to attend a private secondary school, to have a mother of normal corpulence and a concordance between self-image and actual weight status, were protective against excessive consumption of fried foods. Conclusion: This study has displayed prominently the fact that eating
\end{abstract}


too sweet and too fatty concerned respectively $1 / 10$ and $3 / 10$ of pupils in the city of Bobo-Dioulasso. The main modifiable factors of these eating habits included the level of education, the composition of breakfast and the influence of mothers. An intervention program in the form of a Communication for Continuous Behavioral Change intended for pupils and their mothers could help to improve this situation.

\section{Keywords}

Too Sweet/Too Fatty Food Consumption, Young Subject, Pupils

\section{Introduction}

The determinants of diet are of two kinds: individual determinants and collective determinants [1]. Individual determinants include biological factors (age, sex), dietary preferences, and nutritional knowledge and attitudes. Collective determinants are economic, social and environmental determinants. The study of these determinants makes it possible to apprehend the appropriate measures in terms of prevention of overweight and/or cardiovascular diseases particularly, which are the consequences of unhealthy diet and physical behaviors [2] [3] [4]. In Africa, the number of overweight/obese children has nearly doubled between 1990 and 2014, ranking from 5.4 million to 10.6 million [5]. In Burkina Faso, a study conducted in 2010 in the schools of Ouagadougou reported a prevalence of $8.6 \%$ [6]. One of the eating habits that is the cause of obesity is "eating too sweet, too fatty". Little or no study has been done in Africa on the excessive consumption of sweet drinks and fried foods and their determinants. In Algeria, Allam reports an excessive consumption of sweet drinks and fatty foods reaching $60 \%$ and $15 \%$ respectively of pupils [7]. The aim of this study was to determine the frequency and factors associated with their excessive consumption among secondary school pupilsin the city of Bobo-Dioulasso, Burkina Faso's economic capital.

\section{Methods}

This was a cross-sectional analytical study, which took place from March to April 2016, among 1st, 4th and 7th form pupils of public and private schools in the city of Bobo-Dioulasso. The calculation parameters of the sample were as follows: prevalence $8 \%$ (prevalence of overweight/obesity in the schools of Burkina Faso [6], precision 3\%, alpha error 5\% (95\% CI), N = 65,765 pupils, a cluster effect 2. The calculated sample was 1890 pupils, distributed to 630 pupils per class group of 1 st, 4 th and 7 th form in order to detect a possible gradient according to the level of studies.

Food survey methods were a reminder of the last 24 hours associated with the questionnaire on consumption frequency. Excessive consumption of sweet drinks was defined as a consumption of more than 3 sweet drinks (soda) or su- 
gary juice per day $(\sim 33 \mathrm{cl}-3)$; and excessive consumption of fried food as a consumption of more than one ration of fried food/food cooked in oil per day [4].

Through logistic regression method, individual sociodemographic and clinical factors, significantly associated with the excessive consumption of sweet drinks and fried foods, with a significance level of $5 \%$ were identified.

\section{Results}

A total of 1993 pupils, distributed as follows, were interviewed: 649 in 1st form, 673 in 4 th form and 671 in 7 th form.

\subsection{General Characteristics of Pupils}

The mean age of the pupils was $17.5 \pm 3.6$. The mean age per class group was $13.6 \pm 1.5$ years for the 1 st form, $17.5 \pm 1.8$ years for the 4 th form, and $21.3 \pm 2.0$ years for the 7 th form.

More than half of the pupils were female, $56.6 \%(\mathrm{n}=1128)$, or a sex ratio of 0.8 .

Among pupils' parents, $37.9 \%$ of fathers were stoutly built against $45.6 \%$ of mothers.

The prevalence of overweight was 7.3\% $(n=146)$, of which $5.9 \%$ of overweight and $1.4 \%$ of obese. Pupils' self-image of their actual body size was concordant in $46.0 \%$ of cases $(n=916)$.

The number of pupils with a sedentary behavior (i.e. more than 2 hours per day sitting in front of a screen: television, phone, video games, etc.) was 419 , that is a frequency of $21.0 \%$; this frequency was comparable between girls $(21.3 \%)$ and boys (20.7\%), $\mathrm{p}=0.8$.

Half of the students, that is $51.0 \%(\mathrm{n}=1017)$, were practicing a regular physical activity apart from school physical education and sports program.

Among the respondents, $47.0 \%(n=590)$ had a good knowledge of obesity and its risks, while $11.5 \%(\mathrm{n}=229)$ wanted to get fatter.

\subsection{Characteristics of Excessive Consumption of Sweet Drinks}

The excessive consumption of sweet drinks concerned 253 pupils that is $12.7 \%$. After a multivariate analysis, the factors independently associated with this excessive consumption were female sex, sedentary lifestyle, desire to gain weight, lean or normal corpulence of mothers, and lunch intake (Table 1). This consumption was not associated with body mass index (BMI). It tended to decrease with the level of education; thus, it was noted a frequency of $16.3 \%$ in 1 st form, $13.1 \%$ in 4 th form and $8.8 \%$ in 7 th form. But this trend was at the limit of statistical significance $(\mathrm{p}=0.05)$.

\subsection{Characteristics of Excessive Consumption of Fried Foods}

The excessive consumption of fried foods concerned about 561 pupils or $28.2 \%$. 
Table 1. Determinants of excessive consumption of sugary drinks among secondary school pupils in urban Bobo-Dioulasso, Burkina Faso, 2016.

\begin{tabular}{|c|c|c|c|c|c|}
\hline \multirow[t]{2}{*}{ Factor } & \multicolumn{5}{|c|}{ Excessive consumption of sugary drinks } \\
\hline & $\mathrm{n}(\%)$ & $\begin{array}{l}\text { Brut OR } \\
\text { (CI95\%) }\end{array}$ & $\mathrm{p}$ & $\begin{array}{l}\text { Ajusted OR } \\
\text { (CI95\%) }\end{array}$ & p \\
\hline Sex & & & $3 \times 10^{-3}$ & & 0.013 \\
\hline Boys & $88(10.17)$ & 1 & & 1 & \\
\hline Girls & $165(14.63)$ & $1.5(1.14-1.99)$ & & $1.44(1.08-1.93)$ & \\
\hline School & & & 0.840 & & \\
\hline Public & $112(12.53)$ & 1 & & & \\
\hline Private & $141(12.83)$ & $1.0(0.79-1.34)$ & & & \\
\hline Form & & & $2 \times 10^{-4}$ & & 0.051 \\
\hline 1 st & $106(16.33)$ & $2.0(1.44-2.84)$ & & $1.59(1.09-2.31)$ & \\
\hline 4th & $88(13.08)$ & $1.5(1.10-2.21)$ & & $1.32(0.92-1.91)$ & \\
\hline 7th & $59(8.79)$ & & & 1 & \\
\hline BMI & & & 0.588 & & \\
\hline Overweight/obesity & $14(11.38)$ & 1 & & & \\
\hline Thin & $82(13.83)$ & $0.9(0.65-1.16)$ & & & \\
\hline Normal & $157(12.29)$ & $0.8(0.44-1.46)$ & & & \\
\hline Exercice & & & $3 \times 10^{-3}$ & & $2 \times 10^{-3}$ \\
\hline Yes & $71(16.95)$ & 1 & & 1 & \\
\hline No & $182(11.56)$ & $1.6(1.2-2.1)$ & & $1.6(1.2-2.2)$ & \\
\hline ObesityKnowledge & & & 0.701 & & \\
\hline $\mathrm{Bad}$ & $81(12.16)$ & 1 & & & \\
\hline Good & $76(12.88)$ & $1.1(0.8-1.5)$ & & & \\
\hline Desire of weight gain & & & $4 \times 10^{-3}$ & & 0.020 \\
\hline No & $210(11.91)$ & 1 & & 1 & \\
\hline Yes & $43(18.78)$ & $1.70(1.19-2.45)$ & & $1.6(1.1-2.3)$ & \\
\hline Mother'sbuild & & & $4 \times 10^{--4}$ & & 0.025 \\
\hline Overweight/obesity & $72(9.28)$ & 1 & & 1 & \\
\hline Thin & $128(14.27)$ & $1.6(1.2-2.2)$ & & $1.4(1.1-1.9)$ & \\
\hline Normal & $51(17.41)$ & $2.1(1.4-3.0)$ & & $1.7(1.1-2.5)$ & \\
\hline Father'sbuild & & & 0.156 & & 0.812 \\
\hline Overweight/obesity & $113(11.33)$ & 1 & & 1 & \\
\hline Thin & $101(13.67)$ & $1.2(0.9-1.7)$ & & $1.1(0.8-1.5)$ & \\
\hline Normal & $33(15.42)$ & $1.4(0.9-2.2)$ & & $1.0(0.7-1.6)$ & \\
\hline Self-image vs weight status & & & 0.166 & & 0.990 \\
\hline No concordance & $147(13.65)$ & 1 & & 1 & \\
\hline Concordance & $106(11.57)$ & $0.83(0.63-1.08)$ & & $1.0(0.7-1.3)$ & \\
\hline Breakfeastintake & & & $10^{-3}$ & & $3 \times 10^{-3}$ \\
\hline No & $69(9.43)$ & 1 & & 1 & \\
\hline Yes & $184(14.60)$ & $1.6(1.25-2.20)$ & & $1.6(1.2-2.1)$ & \\
\hline
\end{tabular}


Females, being in 1st form or 4th form, physical activity and breakfast intake were independently associated with this excessive consumption.

On the other hand, the fact to attend a private secondary school, to have a mother of normal corpulence and a concordance between self-image and actual weight status, were protective against excessive consumption of fried foods (Table 2). This consumption was not associated with BMI.

\section{Discussion}

The purpose of this study was to illuminate the individual behaviors of pupils in order to draw lessons for the prevention of cardiovascular diseases. Thus, the collective determinants of food behavior (environmental, social, and economic) that go beyond the scope of our study have not been addressed. However, their place is fundamental in a comprehensive prevention program.

Among the pupils, $12.7 \%$ consumed sweet drinks in excess. Daboné reported in 2011, a consumption of "unnecessary" food in the form of sweet things in $18.3 \%$ of schoolchildren in Ouagadougou [8]. Frequencies higher than ours were reported by Allam in Algeria and by the HBSC survey (Health Behavior in School-Aged Children) in France which found respectively 60\% and 27.3\% [7] [9]. The high socio-economic status of these countries compared to ours, and the greater availability of sweet products at home, could explain these differences.

In our study, girls consumed significantly more sweet drinks than boys. But HBSC survey reported a male predominance [9]. The consumption of sweet drinks is linked to the time spent in front of video games and television, and therefore to a sedentary behavior [10] [11], as we found it. In HBSC survey, sedentary lifestyles were predominantly male [9], which could explain this predominance also for the consumption of sweet drinks in this survey. We noticed that the excessive consumption of sweet drinks tended to decrease with the level of education. These results differ from those of HBSC survey where this consumption increased with the level of education, but also not significantly [6].

The consumption of fried foods was excessive in $28.2 \%$ of cases. Allam found a frequency of 15\% among Algerian pupils [7]. The availability, accessibility and relative low cost of fried foods near secondary schools, as we found it during the survey, could contribute to this trend. These foods have a high caloric value compared, in equal proportion, to raw, boiled, grilled or smoked foods; they thus contribute to the risk of developing obesity [3] [4].

The main modifiable factors associated with these long-term harmful consumptions were breakfast intake, level of education and, indirectly, the influence of mothers.

It is recognized that the family is very important for children's food choices and eating habits [12]. Thus, for Daboné, the father's influence was associated with the consumption of "unnecessary" foods while the mother influenced the consumption of "healthy" foods [8]; Allam reported that parental obesity was 
Table 2. Determinants of excessive consumption of fried foods among secondary school pupils in urban Bobo-Dioulasso, Burkina Faso, 2016.

\begin{tabular}{|c|c|c|c|c|c|}
\hline \multirow[b]{2}{*}{ Factors } & \multirow[b]{2}{*}{$\mathrm{n}(\%)$} & \multicolumn{4}{|c|}{ Excessive consumption of fried foods } \\
\hline & & $\begin{array}{l}\text { Brut OR } \\
\text { (CI 95\%) }\end{array}$ & $\mathrm{p}$ & $\begin{array}{l}\text { Ajusted OR } \\
\text { (CI 95\%) }\end{array}$ & $\mathrm{p}$ \\
\hline Sex & & & $10^{-3}$ & & $2 \times 10^{-3}$ \\
\hline Boys & $209(24.16)$ & 1 & & 1 & \\
\hline Girls & $352(31.21)$ & $1.42(1.16-1.74)$ & & $1.68(1.20-2.34)$ & \\
\hline School & & & 0.019 & & 0.020 \\
\hline Public & $275(30.76)$ & 1 & & 1 & \\
\hline Private & $286(26.02)$ & $0.79(0.65-0.96)$ & & $0.73(0.55-0.95)$ & \\
\hline Form & & & $10^{-4}$ & & $10^{-4}$ \\
\hline 1 st & $263(40.52)$ & $3.55(2.74-4.60)$ & & $2.97(1.83-4.79)$ & \\
\hline 4th & $190(28.23)$ & $2.05(1.57-2.67)$ & & $1.69(1.15-2.49)$ & \\
\hline 7th & $108(16.10)$ & 1 & & 1 & \\
\hline BMI & & & 0.004 & & 0.894 \\
\hline Overweight/obesity & $32(26.02)$ & 1 & & 1 & \\
\hline Thin & $197(33.22)$ & $0.71(0.57-0.87)$ & & $1.07(0.78-1.47)$ & \\
\hline Normal & $332(26.00)$ & $0.71(0.46-1.09)$ & & $1.01(0.57-1.80)$ & \\
\hline Exercice & & & $10^{-3}$ & & 0.043 \\
\hline Yes & $241(24.69)$ & 1 & & 1 & \\
\hline No & $320(31.47)$ & $1.40(1.15-1.70)$ & & $1.39(1.01-1.91)$ & \\
\hline ObesityKnowledge & & & $10^{-3}$ & & 0.278 \\
\hline $\mathrm{Bad}$ & $207(31.08)$ & 1 & & 1 & \\
\hline Good & $135(22.88)$ & $0.66(0.51-0.85)$ & & $1.21(0.86-1.70)$ & \\
\hline $\begin{array}{c}\text { Desire of weight } \\
\text { gain }\end{array}$ & & & 0.380 & & \\
\hline No & $490(27.79)$ & 1 & & & \\
\hline Yes & $70(30.57)$ & $1.14(0.85-1.54)$ & & & \\
\hline Mother'sbuild & & & $10^{-4}$ & & 0.005 \\
\hline Overweight/obesity & $168(21.65)$ & 1 & & 1 & \\
\hline Thin & $283(31.55)$ & $1.19(0.90-1.57)$ & & $1.19(0.82-1.73)$ & \\
\hline Normal & $104(35.49)$ & $0.59(0.48-0.75)$ & & $0.66(0.49-0.89)$ & \\
\hline Father'sbuild & & & 0.008 & & 0.559 \\
\hline Overweight/obesity & $267(26.78)$ & 1 & & 1 & \\
\hline Thin & $208(28.15)$ & $1.52(1.11-2.09)$ & & $1.02(0.65-1.58)$ & \\
\hline Normal & $80(37.38)$ & $0.93(0.75-1.15)$ & & $1.17(0.87-1.56)$ & \\
\hline $\begin{array}{l}\text { Self-image vs } \\
\text { weight status }\end{array}$ & & & $<10^{-3}$ & & 0.010 \\
\hline No concordance & $348(32.31)$ & 1 & & 1 & \\
\hline Concordance & $213(23.25)$ & $0.63(0.52-0.77)$ & & $0.68(0.51-0.91)$ & \\
\hline Breakfeastintake & & & $10^{-3}$ & & 0.004 \\
\hline No & $173(23.63)$ & 1 & & 1 & \\
\hline Yes & $388(30.79)$ & $1.44(1.16-1.77)$ & & $1.53(1.15-2.03)$ & \\
\hline
\end{tabular}


positively associated with the risk of child obesity [10]. It has been shown that children and adolescents generally understand the relationship between diet and health [12], and this increases with age and the level of education. The association between breakfast intake and excessive consumption of sweet drinks and fried foods may be linked to the choice of foods offered by parents or available at this moment of the day.

All of these factors can be changed through an effective communication for a behavioral change. The link with pupils' level of education, both for sweet drinks (even at the limit of statistical significance) and fried foods, challenges the content of education; as a matter of fact, sufficient place should be given to courses on NTDs as part of the teaching of Life and Earth Sciences in secondary schools. That is why, in response to the growing burden of NTDs, the Global Strategy for Diet, Physical Exercise and Health adopted by World Health Assembly since 2004, among other measures, calls on Member States to develop and implement school policies and programs aiming to promote a healthy diet and to increase physical exercise [2].

\section{Conclusion}

This study has displayed prominently the fact that eating too sweet and too fatty concerned respectively $1 / 10$ and $3 / 10$ of pupils in the city of Bobo-Dioulasso. The main modifiable factors of these eating habits included the level of education, the composition of breakfast and the influence of mothers. An intervention program in the form of a Communication for Continuous Behavioral Change intended for pupils and their mothers, as well as a review of Life and Earth Sciences Curriculum, in order to give sufficient place to NTDs, would help to improve this situation.

\section{Acknowledgements}

UEMOA Support Program for Higher Education.

\section{References}

[1] Taylor, J.P., Evers, S. and McKenna, M. (2005) Determinants of Healthy Eating in Children and Youth. Canadian Journal of Public Health, 96, S22-S29.

[2] WHO (2008) Implementation of the Global Strategy on Diet, Physical Activity and Health. http://www.who.int/dietphysicalactivity/schools/en/

[3] Sayon-Orea, C., Carlos, S. and Martínez-Gonzalez, M.A. (2015) Does Cooking with Vegetable Oils Increase the Risk of Chronic Diseases?: A Systematic Review. British Journal of Nutrition, 113, S36-S48. https://doi.org/10.1017/S0007114514002931

[4] Gadiraju, T.V., Patel, Y., Gaziano, J.M. and Djoussé, L. (2015) Fried Food Consumption and Cardiovascular Health: A Review of Current Evidence. Nutrients, 7, 8424-8430. https://doi.org/10.3390/nu7105404

[5] WHO. Obesity. http://www.who.int/topics/obesity/en/

[6] Kouéta, F., Dao, L., Dao, F., et al. (2011) Factors Associated with Overweight and Obesity in Children in Ouagadougou (Burkina Faso). Cahier Santé, 21, 227-231. 
[7] Allam, F., Sais, Z., Ouchfoun, A., et al. (2011) Etude du surpoids, de l'obésité et des facteurs associés au surpoids chez les élèves du cycle moyen, scolarisés dans les écoles publiques de l'EPSP Bouzareah. SEMEP, Alger.

http://www.sante.dz/semep_epsp_bouzareah.pdf

[8] Daboné, C. (2010) Poor Nutritional Status of Schoolchildren in Urban and Peri-Urban Areas of Ouagadougou (Burkina Faso).

https://www.ncbi.nlm.nih.gov/pubmed/?term=Poor+nutritional+status+of+schoolc $\underline{\text { hildren+in+urban+and+peri-urban+areas+of+Ouagadougou }}$

[9] Dupuy, M., Escalon, H. and Jouret, B. (2010) Health Behaviour in School-Aged Children (HBSC).

http://inpes.santepubliquefrance.fr/CFESBases/catalogue/pdf/1412.pdf

[10] Allam, O., Oulamara, H. and Agli, A.N. (2016) Prevalence and Risk Factors of Overweight among School Children in a City of Eastern Algeria (Constantine). Antropo, 35, 91-102.

[11] Turel, O., Romashkin, A. and Morrison, K.M. (2017) A Model Linking Video Gaming, Sleep Quality, Sweet Drinks Consumption and Obesity among Children and Youth. Clinical Obesity, 7, 191-198. https://doi.org/10.1111/cob.12191

[12] Raine, K.D. (2005) Determinants of Healthy Eating in Canada. Canadian Journal of Public Health, 96, 8-15. 